\title{
Causes of Hypoglycemia in Hospitalized Diabetic Patients Referred to Endocrine Department of a Tertiary Level Hospital of India
}

\begin{abstract}
Indu K $C^{1}$
${ }^{1}$ Department of Endocrinology and Metabolism, Sir Ganga Ram Hospital, New Delhi, India.

ABSTRACT
Introduction: Diabetes mellitus (DM) results from relative deficiency or reduced
effectiveness of endogenous insulin leading to both micro-vascular and macro-vascular
complications. Treatment goal is intensive therapy as early as possible in patients with both
type-1 and type-2 diabetes to bring the HbA1c to less than 7\%. Occurrence of hypoglycemia
in a diabetic patient is a common side effect of treatment. This study was aimed to find the
causes of Hypoglycemia in diabetes patients. Methods: It was hospital based cross-sectional
observational study on admitted diabetes patients with other co-morbid conditions who were
on either oral hypoglycemic agents (OHA) or Insulin. Cause of hypoglycemia was elicited
by history taking and analysis. Results: Out of 36 diabetics included in this study, seven had
severe hypoglycemia, 22 had moderate to mild hypoglycemia. Most of them had various
comorbidities. The causes of hypoglycemic episodes were varied. Conclusion:
Hypoglycemia can occur despite cautious treatment protocol especially in diabetics with
organ dysfunction, which can be prevented by alert and well-coordinated medical team.
Keywords: hypoglycemia; diabetes mellitus; insulin; oral hypoglycemic agents
\end{abstract}

\section{INTRODUCTION}

Diabetes mellitus (DM) results from lack/ reduced effectiveness of insulin and with intensive therapy HbAlc goal should be less than $7 \%$. Diabetes Control and Complications Trial (DCCT) and the Stockholm Diabetes Intervention Study (SDIS) showed that intensive therapy reduced the incidence/ progression of micro-vascular complications in patients with type- $1 \mathrm{DM}^{1,2}$.

The United Kingdom Prospective Diabetes Study (UKPDS) and the Kumamoto study determined that stricter glycemic control could be useful in delaying the onset and progression of diabetic micro-vascular/macro-vascular complications as well in patients with type-2 diabetes $^{3,4}$. Current insulin secretagogues or conventional subcutaneous insulin delivery system cannot replace the physiology of $B$-cell. The risk of hypoglycemia increases with absolute/relative insulin excess and compromised glucose regulation ${ }^{5}$. In earlier stages of type-2 diabetes when glucose counter-regulatory responses are still functional, hypoglycemia is less common than in type-1 diabetic patients. Since progressive B-cell failure is a key pathophysiological

Correspondence: Indu KC, Department of Endocrinology and Metabolism, Sir Ganga Ram Hospital, New Delhi, India. Email :drindukc@gmail.com 
feature of type- 2 diabetes, the characteristics of disease and frequency of hypoglycemic episodes eventually approach that of type-1 diabetes $^{6}$. Hypoglycemia begets hypoglycemia ${ }^{7}$ and overtime worsens to severe hypoglycemia, nocturnal hypoglycemia and arrhythmias ${ }^{8}$. Occurrence of hypoglycemia is associated with potentially serious physical and psychological consequences.

This study was aimed to find the causes of hypoglycemia in admitted patients and to prepare the team for early recognition and prompt management of hypoglycemia at our centre.

\section{METHODS}

This was hospital based cross-sectional and observational study conducted at Sir Ganga Ram Hospital (SGRH). The study period was September 2014 to April 2015. All consecutive patients meeting the eligibility criteria during the study period were included. Inclusion criteria were patients with various medical conditions along with uncontrolled DM who were consulted with endocrine department for control of sugar and patients on insulin or OHAs. Exclusion criteria were extreme of ages (less than 18 and more than 95 years) and gestational diabetes. Both Type-1 and Type-2 DM were included in the study.

Thorough evaluation was done by history, physical examination, and necessary laboratory investigations. Demographic variables included age, sex , history of OHA/Insulin, intake of food and last dose of drugs timing was recorded. Past history of hypoglycemia was documented.

All the blood samples were collected by the nursing staff at the time of clinical/incidental hypoglycemia using glucometer that was further confirmed by biochemistry.

\section{RESULTS}

Out of the 36 Patients analyzed, 24 were male and 12 were female, ranging from 35 to 91 years of age (table 1). Thirty of them had type-2 DM and 6 had type 1 DM. Most of them

Table 1: Distribution of patient according to age group

\begin{tabular}{l|r|r|r|r|r|}
$\begin{array}{l}\text { Age } \\
\text { (Year) }\end{array}$ & $30-40$ & $40-50$ & $50-60$ & $70-80$ & $80-90$ \\
\hline Nos. & 5 & 0 & 23 & 6 & 2 \\
\hline
\end{tabular}

Table 2: HbA1c levels of patients under study. HbA1c up to 6 suggest blood glucose well controlled, 6-8 fairly controlled, 8-10 poorly controlled and more than 11 uncontrolled.

\begin{tabular}{|c|c|c|c|c|}
\hline HbAlc & Up to 6 & $6-8$ & $8-10$ & more than 11 \\
\hline Nos & 3 & 13 & 14 & 6 \\
\hline
\end{tabular}

Table 3: Co-morbidities of patients

\begin{tabular}{|l|c|}
\hline Conditions of Patient & Nos. \\
\hline Deranged renal function & 17 \\
\hline $\begin{array}{l}\text { Deranged liver function due to acute/ } \\
\text { chronic liver disease }\end{array}$ & 4 \\
\hline $\begin{array}{l}\text { Triopathy (retinopathy, neuropathy, } \\
\text { nephropathy) }\end{array}$ & 7 \\
\hline Left ventricular failure & 3 \\
\hline ACS with CKD and CAD & 4 \\
\hline Infections & $\mathbf{1 0}$ \\
\hline Meningoencephalitis & 1 \\
\hline Cholecystis & 2 \\
\hline Urosepsis & 3 \\
\hline COAD & 2 \\
\hline Pulmonary Aspergilloma & 1 \\
\hline
\end{tabular}


Table 4: Blood glucose level (BGL) in $\mathrm{mg}$ as measured by glucometer during hypoglycemia episodes. Blood glucose $20-40$ is severe hypoglycemia, 41-60 is moderate and $61-70$ is mild hypoglycemia.

\begin{tabular}{|l|r|r|r|r}
\hline BGL & $20-40$ & $41-60$ & $61-70$ & $71-80$ \\
\hline Nos & 6 & 19 & 10 & 1 \\
\hline
\end{tabular}

were admitted with poor sugar control, mean HbA1c was 8.4 (table 2). Most patients also had co-morbidities (table 3). Severity of hypoglycemia is shown in table 4 and causes in table 5.

One patient remained unconscious for 1 hour, 2 patients went to hypo repeatedly within 30-60 minutes and they were patients diagnosed with liver failure awaiting liver transplantation. Fifteen patients had blood glucose level (BGL) more than $100 \mathrm{mg}$ after 15 min while 21 patients had BGL more than 100 $\mathrm{mg}$ after $30 \mathrm{~min}$.

\section{DISCUSSION}

Hypoglycemia is characterized by "Whipple triad," that includes documentation of low blood sugar, presence of symptoms and reversal of these symptoms when the blood glucose level is restored to normal. Diabetes mellitus results from lack or reduced effectiveness of endogenous insulin, which results into hyperglycemia and metabolic derangements, which further leads to both micro vascular and macro vascular complications. Hypoglycemia, and the fear and potentially disastrous consequences that follow, is well recognized in patients with type 1 diabetes; its importance in Type 2 diabetes mellitus (DM) is often underestimated and less well appreciated ${ }^{3,4}$. Although therapy is initiated to control hyperglycemia by use of insulin or OHAs, current insulin secretagogues
Table 5: Causes of hypoglycemia

\begin{tabular}{|c|c|}
\hline Causes & Nos \\
\hline $\begin{array}{l}\text { Insulin dose mismatch with } \\
\text { carbohydrate intake }\end{array}$ & 13 \\
\hline New NPO Status & 10 \\
\hline $\begin{array}{l}\text { Transfer to other unit OT/HDU/ICU/ } \\
\text { Cath. lab after insulin }\end{array}$ & 8 \\
\hline $\begin{array}{l}\text { Transfer from other hospital after } \\
\text { Insulin without food }\end{array}$ & 2 \\
\hline $\begin{array}{l}\text { Self medication insulin/OHA even } \\
\text { after admission }\end{array}$ & 7 \\
\hline Insulin dose overlap & 10 \\
\hline Drug dispensing error by staff & \\
\hline $\begin{array}{l}\text { Sudden steroid reduction in } \\
\text { transplant patient }\end{array}$ & 2 \\
\hline $\begin{array}{l}\text { Reduced steroid but past } \\
\text { neutralizing dose of Insulin }\end{array}$ & 1 \\
\hline $\begin{array}{l}\text { Monitoring error (to hold } \\
\text { insulin Infusion) }\end{array}$ & 1 \\
\hline $\begin{array}{l}\text { Basal dose overlapped by } \\
\text { bolus Insulin }\end{array}$ & 1 \\
\hline New Problem in patient & \\
\hline Nausea/vomiting after Insulin & 1 \\
\hline Meal skipped after Insulin & 1 \\
\hline \multicolumn{2}{|l|}{ Other causes } \\
\hline Critically ill patient & 30 \\
\hline $\begin{array}{l}\text { Endocrine deficiency } \\
\text { (hypothyroidism) }\end{array}$ & 3 \\
\hline Effect of General anesthesia & 4 \\
\hline Post pancreatectomy status & 1 \\
\hline
\end{tabular}

or conventional subcutaneous insulin delivery system cannot replace the physiology of $B$-cell so occurrence of hypoglycemia in a diabetic patient is a common side effect of treatment that is most feared by patient. Hypoglycemia is an unpleasant experience associated with potentially serious physical and psychological 
consequences. It's a fatal condition that worries not only the patient and their relative but also to the treating physician/team. Doctor, Nurse and health care team should be vigilant in detecting, treating and preventing hypoglycemia while treating diabetic patients. Certain oral hypoglycemic agents like Sulphonylureas (Glyburide and Metformin) are considered nasty in hypoglycemic patient and significantly dangerous to the developing neuroglycopenia especially in serious patients with critical illness and organ dysfunction. Recent Indian studies show that only $20.4 \%$ of diabetes care physicians set HbAlc of less than $7 \%$ as target for their patients ${ }^{9}$ and only $19.7 \%$ of patients achieve this value ${ }^{10}$. This clinical criteria has often been attributed to presence or fear of hypoglycemia, both among physicians and patients ${ }^{11}$. It can thus limit the aggressiveness of drug therapy, decrease adherence to diet and reduce patients' willingness to take medications as directed ${ }^{12}$. Hypoglycemic symptoms may also lead to increased calorie intake and worsening of glycemic control.

According to ADA (American Diabetes Association) Guideline for management of hypoglycemia all the patients at risk for hypoglycemia should be asked about symptomatic and asymptomatic hypoglycemia at each encounter ${ }^{13}$.

Canadian retrospective studies have suggested a link between frequent severe hypoglycemia (5 or less episodes since diagnosis) and a decrease in intellectual performance. These changes were small but, depending on an individual's occupation, could be clinically meaningful. Prospective studies in type-1 diabetes have not found an association between intensive insulin therapy and cognitive function $^{14-16}$. A meta-analysis concluded that lowered cognitive performance in people with type-1 DM appears to be associated with the presence of micro vascular complications but not with the occurrence of severe hypoglycemic episodes or with poor metabolic control ${ }^{17}$.

Association between frequency of hypoglycemia and glycemic control has been consistently reported in the past. Hypoglycemia episodes were observed more frequently in intensive therapy arms of large series of diabetes studies like United Kingdom Prospective Diabetes Study (UKPDS), Action to Control Cardiovascular Risk in Type 2 Diabetes (ACCORD), Action in Diabetes and Vascular Disease (ADVANCE), and Veterans Affair Diabetic Trial (VADT) ${ }^{18-20}$.

\section{CONCLUSION}

Commonest causes of hypoglycemia in patients with diabetes mellitus are drug dispensing error, Insulin/OHA dose and timing, mismatch between carbohydrate intake and insulin dose and prolonged NPO before operations. Some other causes were mismatch in insulin therapy with the proportion of carbohydrate intake due to poor oral intake after insulin administration or due to vomiting, transfer to OT, Hemodialysis, Endoscopy unit, USG etc which all could have been avoided to prevent hypoglycemia and can be achieved through coordination between treating team and on duty staff.

\section{ACKNOWLEDGEMENT}

I am thankful to my Professor Dr Surinder Kumar and Dr Sudhir Tripathi, Department of Endocrinology and Metabolism for their guidance and support throughout this study in SGRH. 


\section{REFERENCES}

1. The effect of intensive treatment of diabetes on the development and progression of long-term complications in insulindependent diabetes mellitus. The Diabetes Control and Complications Trial Research Group. N Engl J Med 1993; 329:977-86. DOI: http://dx.doi.org/10.1056/ NEJM199309303291401

2. Reichard P, Britz A, Carlsson P, Cars I, Lindblad L, Nilsson BY,et al. Metabolic control and complications over 3 years in patients with insulin dependent diabetes (IDDM): The Stockholm Diabetes Intervention Study (SDIS). J Intern Med 1990;228:511-7. DOI: http://dx.doi.org/ $\underline{10.1111 / j .1365-2796.1990 . t b 00271 . x}$

3. UK Prospective Diabetes Study (UKPDS) Group. Intensive blood-glucose control with sulphonylureas or insulin compared with conventional treatment and risk of complications in patients with type 2 diabetes (UKPDS 33 ). Lancet 1998;352:837-53. DOI: http://dx.doi.org/ 10.1016/S0140-6736(98)07019-6

4. Shichiri M, Kishikawa H, Ohkubo Y, Wake N. Long-term results of the Kumamoto Study on optimal diabetes control in type 2 diabetic patients. Diabetes Care 2000;23Suppl 2:B21-9.

5.Cryer PE. Hypoglycaemia: The limiting factor in the glycaemic management of Type I and Type II diabetes. Diabetologia 2002;45:937-48. DOI: http://dx.doi.org/ $\underline{10.1007 / \mathrm{s} 00125-002-0822-9}$

6. Zammitt NN, Frier BM. Hypoglycemia in type 2 diabetes: Pathophysiology, frequency, and effects of different treatment modalities. Diabetes Care 2005;28:2948-61. DOI: MJSBH Vol 15 Issue 1 Jan- Jun 2016 http://dx.doi.org/10.2337/diacare. $\underline{28.12 .2948}$

7. Cryer PE. Hypoglycemia begets hypoglycemia in IDDM. Diabetes 1993;42:1691-3. DOI: http://dx.doi.org/ $\underline{10.2337 / \text { diab.42.12.1691 }}$

8. Clark AL, Best CJ, Fisher SJ. Even silent hypoglycemia induces cardiac arrhythmias. Diabetes 2014;63:1457-9. DOI: http:// dx.doi.org/10.2337/db14-0108

9. Moses CR, Seshiah V, Sahay BK, Kumar A, Asirvatham AJ, Balaji V, et al. Baseline results indicate poor glycemic control and delay in initiation and optimization of insulin therapy: Results from the improving management practices and clinical outcomes in type 2 diabetes study. Indian J Endocrinol Metab 2012;16(Suppl 2):S432-3.

10. Mohan V, Seshiah V, Sahay BK, Shah SN, Rao PV, Banerjee S, et al. Current status of management of diabetes and glycaemic control in India: Preliminary results from the DiabCare India 2011 study. Diabetes 2012;61:A645-77.

11. Ahrén BO. Avoiding hypoglycemia: A key to success for glucose-lowering therapy in type 2 diabetes. Vasc Health Risk Manag 2013;9:155-63. DOI: http://dx.doi.org/ 10.2147/VHRM.S33934.

12. Amiel SA, Dixon T, Mann R, Jameson K. Hypoglycaemia in type 2 diabetes. Diabet Med 2008;25:245-54 DOI: http://dx.doi.org/ 10.1111/j.1464-5491.2007.02341.x

13. American Diabetes Association. Standards of medical care in diabetes-2014. Diabetes Care. 2014;37(suppl 1):S14-S80 DOI: http://dx.doi.org/10.2337/dc14-S014 
14. The Diabetes Control and Complications Trial Research Group Effects of intensive diabetes therapy on neuropsychological function in adults in the Diabetes Control and Complications. Trial Ann Intern Med 124; 1996: 379- 388

15. P. Reichard M. Pihl Mortality and treatment side-effects during long-term intensified conventional insulin treatment in the Stockholm Diabetes Intervention Study .Diabetes 43; 1994: 313- 317

16. Diabetes Control and Complications Trial/ Epidemiology of Diabetes Interventions and Complications Study Research Group A.M. Jacobson G. Musen C.M. Ryan Long-term effect of diabetes and its treatment on cognitive function NEngl J Med. 2009;361:1914.

17. A.M. Brands G.J. Biessels E.H. de Haan The effects of type1 diabetes on cognitive performance: a meta-analysis. Diabetes Care 28; 2005: 726- 735. DOI: http:// dx.doi.org/10.2337/diacare.28.3.726

18. Gerstein HC, Miller ME, Byington RP, Goff DC Jr, Bigger JT, Buse JB, et al.; Action to Control Cardiovascular Risk in Diabetes Study 20.Group. Effects of intensive glucose lowering in type 2 diabetes. N Engl J Med 2008;358:2545-59. DOI: http://dx.doi.org/ 10.1056/NEJMoa0802743

19. Patel A, MacMahon S, Chalmers J, Neal $\mathrm{B}$, Billot L, Woodward $\mathrm{M}$, et al.; ADVANCE Collaborative Group. Intensive blood glucose control and vascular outcomes in patients with type 2 diabetes. $\mathrm{N}$ Engl J Med 2008;358:2560-72. DOI: http:// dx.doi.org/10.1056/NEJMoa0802987
20. Duckworth W, Abraira C, Moritz T, Reda $\mathrm{D}$, Emanuele N, Reaven PD, et al. Glucose control and vascular complications in veterans with type 2 diabetes. N Engl J Med 2009;360:129-39. DOI: http://dx.doi.org/ 10.1056/NEJMoa0808431 